\title{
Travel-Related Economic Burden of Chimeric Antigen Receptor T Cell Therapy Administration by Site of Care
}

\author{
Sophie Snyder (D) - Tina Albertson · Jacob Garcia · Matthew Gitlin • \\ Monika P. Jun
}

Received: April 1, 2021 / Accepted: June 21, 2021 / Published online: July 18, 2021

(C) The Author(s) 2021

\section{ABSTRACT}

Introduction: We previously examined how expanding access to chimeric antigen receptor (CAR) T cell therapy administration sites impacted patient travel distances and time. In the current study, we estimated travel-related economic burden associated with site-of-care options among patients with relapsed/refractory diffuse large B cell lymphoma.

Methods: We used geographic information system methods to quantify travel-related economic burden across three site-of-care scenarios: academic hospitals; academic and community multispecialty hospitals; and academic and community multispecialty hospitals plus nonacademic specialty oncology network centers. Socioeconomic status, administration sites, and

Tina Albertson was an employee of Juno Therapeutics, a Bristol-Myers Squibb Company, at the time the study/ research was conducted.

Supplementary Information The online version contains supplementary material available at https:// doi.org/10.1007/s12325-021-01839-y.

S. Snyder $(\bowtie) \cdot$ M. Gitlin

BluePath Solutions, Los Angeles, CA, USA

e-mail: ssnyder@qualiabio.com

T. Albertson · J. Garcia

Bristol Myers Squibb, Seattle, WA, USA

M. P. Jun

Bristol Myers Squibb, Princeton, NJ, USA county of residence were derived from the US Census Bureau and publicly available sources. Travel costs were based on governmental guidelines, US census wage data, and Bureau of Transportation Statistics. Travel distance and time to the nearest CAR T cell therapy administration sites were estimated from previous research.

Results: Total national estimated costs associated with traveling for CAR T cell therapy were \$21.1 million if CAR T cell therapy was offered exclusively in academic hospitals, and \$14.7 million if expanded to include community hospitals plus nonacademic specialty oncology network centers, representing a \$6.5-million reduction associated with expanding access to eligible patients. The largest cost-saving component was lodging/meals. Regional and demographic cost differences were statistically significant between academic hospitals and nonacademic hospitals/ specialty oncology centers. In all scenarios, patients living below the federal poverty level (FPL) had higher weighted mean total costs versus patients living above the FPL. White and Native American patients were estimated to have the highest weighted mean total costs across race/ ethnicity groups. For all subgroups, costs were reduced by expanding access beyond academic hospitals.

Conclusion: CAR T cell therapy is currently restricted to academic hospitals; total travel costs could be substantially decreased if access is expanded to nonacademic hospitals and specialty oncology centers. Patients in rural areas and those 
living below the FPL are particularly disadvantaged by restricted access.

Keywords: Access to health care; CAR T cell therapy; Diffuse; Economic model; Geographical information systems; Health care inequalities; Lymphoma; Policy

\section{Key Summary Points}

Why carry out this study?

In a companion study, we showed that expanding access to chimeric antigen receptor (CAR) T cell therapy administration sites can help to reduce patient travel distances and time.

In the current study, we build on these findings by estimating the travel-related economic burden associated with expanding site-of-care options among patients with relapsed or refractory diffuse large B cell lymphoma.

Expansion of CAR T cell therapy sites-ofcare in the continental USA will reduce travel-related economic burden.

\section{What was learned from this study?}

The economic burden associated with traveling for CAR T cell therapy in the USA was estimated to be $\$ 21.1$ million if CAR T cell therapies were offered exclusively in academic hospitals, and $\$ 14.7$ million if offered in academic and community hospitals plus nonacademic specialty oncology network centers, representing a \$6.5-million reduction in health system costs associated with expanding access to eligible patients.

Under the current treatment environment, CAR T cell therapy is restricted to academic hospitals; total travel costs could be substantially decreased if access is expanded to nonacademic hospitals and specialty oncology centers.
Patients in rural areas and those living below the federal poverty line are particularly disadvantaged by restricted access.

\section{DIGITAL FEATURES}

This article is published with digital features, including a summary slide, to facilitate understanding of the article. To view digital features for this article go to https://doi.org/10.6084/ m9.figshare.14816232.

\section{INTRODUCTION}

In 2016, an estimated 27,650 individuals in the United States (US) were diagnosed with diffuse large B cell lymphoma (DLBCL), a subset of non-Hodgkin lymphoma (NHL) [1]. Survival has improved over the past 2 decades as a result of therapy advances (namely, rituximab) [2], with approximately $60 \%$ of patients surviving to 5 years after diagnosis. Treatment options are still needed for patients with relapsed disease or those who do not respond to early lines of therapy. Treatment with chimeric antigen receptor (CAR) modified $T$ cells has been successful in treating patients with DLBCL, and two approved products are currently availableaxicabtagene ciloleucel and tisagenlecleucel. Other CAR T cell therapies are under investigation for this indication, including lisocabtagene maraleucel. Because CAR T cell therapy is a relatively novel treatment modality, uncertainty and a lack of experience regarding administration-related factors exist. Coupled with its high cost and specialized management protocols, CAR T cell therapy has been limited to certain sites of care (SOCs) that can administer this therapy, potentially restricting patient access. The SOC where patients can access therapy may also be limited on account of contracts between private payers and providers of certain treatments.

Patients with cancer receiving later-line therapy may be particularly vulnerable to travel costs associated with receiving treatment. 
Patients with cancer tend to have greater disability in activities of daily living that may impact their employment status, and older patients may be on fixed incomes [3-5]. Thus, traveling to centers of excellence (defined as recognized centers that meet standards established by a predominant cancer organization based on criteria such as research and adoption of new approaches to treating cancer) [6] may result in a financial burden for these patients and their families and caregivers. As of mid2019, CAR T cell therapy for DLBCL was offered at only 95 locations out of nearly 2400 oncology practices in the US [7]. Most SOC are located in the eastern US, with limited sites on the west coast and even fewer in the midwest [8]. Limited SOC access imposes a heavy burden on patients in underserved areas [9]. Direct travel costs have been estimated to comprise $5-25 \%$ of total patient out-of-pocket costs associated with cancer treatment [10]. Indirect costs resulting from travel, such as productivity and the value of time, comprise an even larger proportion of costs. These direct and indirect out-of-pocket travel costs could have a significant financial impact on patients. Studies have found that patients with cancer are more likely to file for bankruptcy compared with patients without cancer, and this financial burden may translate to relatively poor health outcomes [11-13].

As health care costs are expected to increase for both patients and payers, identifying ways to minimize costs while maximizing access to treatment is of immediate importance $[14,15]$. Specialized oncology centers (e.g., physicianowned ambulatory centers and specialty hospitals) have been recognized as a potential factor in reducing costs and improving patient access and quality of care [16]. In contrast, restricting access to specialized "centers of excellence" has been shown to impose an excess burden on patients, such as those living in nonurban areas, certain ethnic groups (specifically Native Americans), and patients living in the southern US [17].

CAR $T$ cell therapy has been a breakthrough treatment for patients with DLBCL in the thirdor later-line setting [18, 19]. However, the administration of this novel therapy has been to limited to select cancer centers approved by manufacturers and independent institutions. In another study, we quantified estimated travel distance and time to the nearest CAR T cell therapy administration site [9]. Using geographic information system methods, we assessed three SOC scenarios for CAR T cell therapy infusion nationally and stratified by region and demographic variables: (A) academic hospitals only; (B) academic and community multispecialty hospitals; and (C) academic and community multispecialty hospitals plus nonacademic specialty oncology network centers (NASONCs). In this analysis, we estimated the travel costs associated with these three treatment center scenarios.

\section{METHODS}

\section{Data Sources}

The primary data used for this analysis included patient population by county, sites of CAR T cell therapy administration, and travel costs. Patient counts (NHL incidence data) by county of residence were obtained from the Centers for Disease Control and Prevention's National Program of Cancer Registries Cancer Surveillance System and the National Cancer Institute's Surveillance, Epidemiology, and End Results Program. The latest 5-year average (2011-2015) of county-level cancer incidence rate for all stages, all races (including Hispanic), both sexes, and all ages of NHL were used for this analysis. Rates were reported as cases per 100,000 population per year and were age adjusted to the 2000 US standard population. In many cases, the Centers for Disease Control and Prevention suppressed county-level cancer incidence data because of low annual rates. For our analysis, we imputed these suppressed county rates to 1 case per 100,000 . Methods for determining the average and county-level incidence of patients with DLBCL, number of patients with DLBCL receiving third-line therapy selected for CAR T cell therapy, socioeconomic status, and classification of urban/rural residency are described in Snyder et al. [9].

This article does not contain any new studies with human participants or animals performed by any of the authors. 
We used publicly available data on CAR T cell therapy administration sites and county of residence for patients with NHL. Facility addresses and characteristics were obtained from currently available CAR T cell therapy websites $[8,20]$ and oncology center databases [21-23]. The facilities that administered CAR T cell therapy were classified by SOC type: academic hospitals, community multispecialty hospitals, or NASONCs (Fig. S1). A summary of the measures and definitions used in this study are provided in Table S1. Further details of this analysis have been described previously [9].

Cost estimates were applied to travel distance and time using publicly available data sources. Lodging and meals cost data were based on the per diem rates set by the US General Services Administration (GSA) [24]. Average domestic flight costs were from the US Bureau of Transportation Statistics (BTS) [25]. To estimate lost productivity and leisure time, data from the US Bureau of Labor Statistics were applied [25]. Finally, direct mileage costs were estimated using standard mileage rates from the Internal Revenue Service (IRS) [27].

\section{Data Analysis}

We compared travel burden by scenarios of progressively inclusive SOC access. Three scenarios were used: (A) academic hospitals only; (B) academic and community multispecialty hospitals; and (C) any specialized center, which included any approved inpatient or possible outpatient CAR T cell therapy center (academic hospitals, community multispecialty hospitals, and NASONCs). The breakdown of the number of sites by type are shown in Table S2. The scenarios were analyzed at the national and census region levels [28]. Results were also stratified by race/ethnicity and federal poverty level (FPL) by linking county-level demographic distributions to represent patient attributes.

Total travel burden included direct costs (based on mileage wear and tear) and indirect costs (based on lost productivity and leisure time) (Table S3). All patients were assumed to travel with a caregiver, who was presumed to incur separate direct costs, indirect costs, and when applicable, flight and lodging/meal costs [29]. In the base case, $15.2 \%$ of caregivers required separate lodging based on the assumption that some patients were in stable condition and the caregiver was an unrelated paid aide [28]. We assigned a permile-traveled cost using the IRS 2019 standard mileage rates [20]. Patient and caregiver mileages were multiplied by 20 cents per mile driven for medical purposes and 58 cents per mile driven for business use, respectively. Caregiver miles were valued on the basis of a replacement cost approach using the IRS business mileage rate. Indirect costs comprised the value of leisure time for patients and the value of leisure time plus lost productivity for caregivers. Consistent with previous literature [30, 31], the value of leisure time was used (vs lost work productivity) because most patients with DLBCL receiving third-line therapy are aged 60 years or older [32]. We used the foregone wage and a replacement cost approach to estimate indirect caregiver costs. This method used the average of the state minimum wage, the average home health aide wage, and the median private pay cost of hiring a home health aide. The time that patients spent in care/monitoring was not included for the patient or caregiver.

Patients were assumed to travel round trip by car or flight. In the base-case analysis, patients were assigned flight costs if their one-way drive time exceeded $5 \mathrm{~h}$ [33]. We used geographic information system methods to extract round trip flight costs from the patient's nearest airport based on BTS data from the second quarter of 2019 [34]. Patients were assumed to require a hotel stay if they resided more than $60 \mathrm{~min}$ from the nearest administration site in the base case. This assumption was based on a consensus between certain administration sites' websites that stated patients must stay within $30 \mathrm{~min}$ $[35,36]$ and the approved Risk Evaluation and Mitigation Strategies of available CAR T cell therapies that require 2 -h proximity to the SOC. Additionally, a 30-min cutoff is used by the Health Resources and Services Administration when designating Primary Care Health Professional Shortage Areas [37]. Lodging and meal costs were associated with the nearest CAR $\mathrm{T}$ cell therapy administration site based on GSA 
data from fiscal year 2020 [15]. The GSA establishes per diem rates for the lower 48 continental USA, which are the maximum allowed reimbursements for federal employee expenses incurred during official travel. After locating the nearest administration site, it was assumed that patients would either drive directly to the site for each required visit (14 visits in the base case; Fig. 1) or fly or drive to the closest hotel and subsequently drive to the administration site for required visits. Thus, patients who required flights or lodging incurred an additional round trip drive, flight costs, and lodging and meal costs (Fig. S2).

\section{Statistical Analysis}

Statistical analyses were conducted at two levels. Descriptive and correlation analyses were used to examine the change in costs associated with additional SOC access. A weighted mean was used to describe costs because of the unequal county-level distribution of patients with DLBCL. The distance from counties with higher DLBCL incidence contributed more to the final average compared with counties with low incidence. Means were compared between scenarios (but within patient groups) using Wilcoxon rank sum tests with continuity correction. The two-proportion $z$ test was used to test for differences in the proportions of patients required to fly or lodge by scenario. For all statistical tests, a two-tailed $P<0.05$ was considered statistically significant. All statistical analyses were performed using R software (version 3.6.1 [2019-07-05]; R Graphical User Interface system for Windows) [18]. A one-way deterministic sensitivity analysis was performed on key input variables to test the robustness of results (Table S4). Variables included the need to stay nearby for leukapheresis, bridging chemotherapy, scans and laboratory tests, lymphodepletion, CAR T cell therapy administration, monitoring, and short-term (28 days after CAR T cell infusion) follow-up visits.

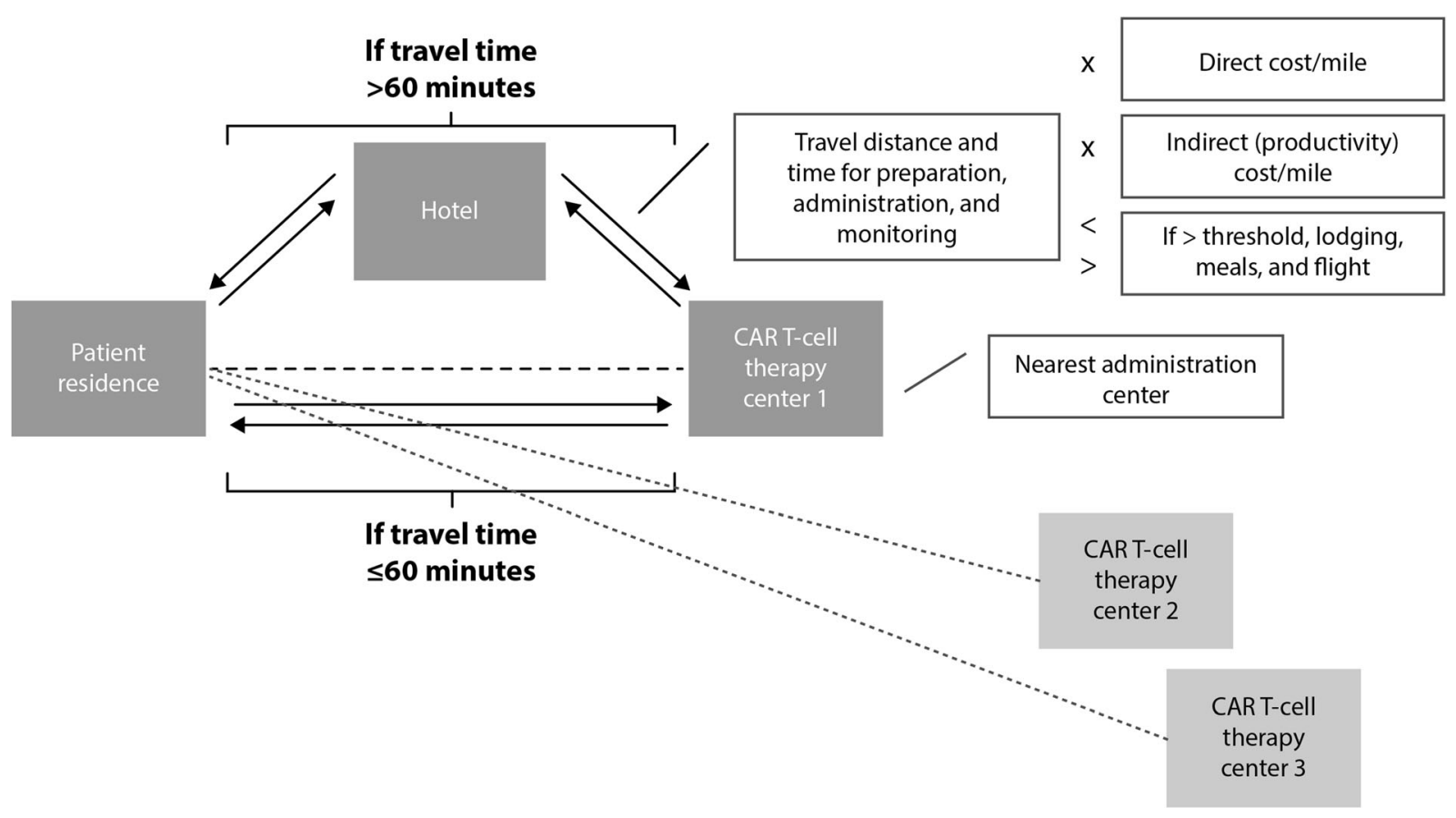

Fig. 1 Base-case threshold model. CAR chimeric antigen receptor 


\section{RESULTS}

\section{Patients}

The analysis included NHL incidence data (2011-2015) from all US states except Kansas, Minnesota, Nevada, Alaska, and Hawaii. From these data, 62,339 unique cases of NHL were identified. Patients with DLBCL receiving thirdline therapy were estimated to comprise 3922 (6.3\%) of the identified patients with NHL in 2015 [38-40].

\section{Travel-Related Costs}

In the base case, total national estimated costs across this annual third-line incident population and their caregivers ranged from $\$ 14.7$ million in scenario C to $\$ 21.1$ million in scenario A, representing a $\$ 6.5$-million reduction associated with expanding access to additional SOCs (Table 1). The largest component of cost savings was lodging and meals $(\$ 4.7$ million in savings from expanding from scenario $\mathrm{A}$ to scenario C). About 30\% $(n=441)$ and $18 \%$ $(n=271)$ fewer patients were estimated to require lodging each year if access was expanded to scenario $C$ and scenario $B$, respectively, compared with scenario A ( $P<0.001$ for both). Similarly, the number of patients that required flights was reduced by approximately $71 \%$ $(n=51)$ by expanding access from scenario A to scenario $C(P<0.001)$. The results for scenario $B$ versus scenario $A$ were not significant. As a proportion of patients, these reductions were statistically significant (Table 1 ).

The estimated national per-patient weighted mean total economic burden for scenario A and scenario B was $\$ 5368(P<0.001)$ and $\$ 4512$ $(P<0.001)$, respectively, compared with $\$ 3738$ for scenario $C$. This represented an estimated travel cost reduction of $\$ 1630$ (30.4\%) and $\$ 856$ (13.8\%) per patient per CAR T cell therapy administration event (Table 2). Regional and demographic differences in estimated costs between scenario $\mathrm{A}$ and scenario $\mathrm{C}$ were statistically significant. The west (Table 2; Fig. 2) and rural regions had the highest estimated weighted mean total burden for scenario A $(\$ 11,037$ and \$7191, respectively). The difference in the estimated weighted mean total cost between scenarios was also highest in the west (scenarios $B$ and $C$ ) and rural regions (scenario $C$ ).

\section{Travel Costs, Socioeconomic Status, and Race/Ethnicity}

For all scenarios, patients living below the FPL were estimated to have a higher weighted mean total cost versus patients living above the FPL; however, the weighted mean for these patients was significantly reduced by expanding access to additional sites (Table 2). Patients of White and Native American race were estimated to have the highest weighted mean total cost across race/ethnicity groups. Costs were significantly reduced for these groups by increasing access from scenario A to scenario C. Expanding access to scenario $B$ decreased the weighted mean cost, but the difference was not statistically significant among the Native American race group.

\section{Sensitivity Analysis}

The one-way deterministic sensitivity analysis supported the conclusion that expanding access from scenario $A$ to scenario $C$ reduced the expected economic burden (Fig. 3). The perpatient weighted mean difference between these scenarios in the sensitivity analysis ranged from \$1207 to \$2011 compared with the basecase results of $\$ 1630$. Results were most sensitive to the required patient proximity to the administration site, which was estimated as $30 \mathrm{~min}$ to $2 \mathrm{~h}$.

In extreme sensitivity testing, results continued to favor scenario C compared with scenario A. In a scenario in which no patients required lodging, the expected weighted mean savings by expanding access to scenario $\mathrm{C}$ was $\$ 905$ ( $\$ 3267$ vs $\$ 2362$ for scenario A vs scenario C, respectively; results not shown). Similarly, removing all flight costs marginally reduced the savings to $\$ 1618$ between scenarios. 
Table 1 National total and weighted mean economic burden per patient and caregiver by category

\begin{tabular}{llllll}
\hline Scenario & Driving-related costs & Indirect costs & Flights & Lodging and meals & Total costs \\
\hline
\end{tabular}

Total costs

(A) Academic hospitals only

Patients who required flights and/or lodging/meals, \%

$1.8 \quad 37.3$

Costs

$\begin{array}{llllll}\text { Patient } & \$ 548,671 & \$ 1,495,674 & \$ 31,324 & \$ 10,207,995 & \$ 12,283,663 \\ \text { Caregiver } & \$ 1,591,145 & \$ 2,959,243 & \$ 31,324 & \$ 4,257,495 & \$ 8,839,207 \\ \text { Total } & \$ 2,139,815 & \$ 4,454,917 & \$ 62,648 & \$ 14,465,490 & \$ 21,122,871 \\ & \text { Ref. } & \text { Ref. } & \text { Ref. } & \text { Ref. } & \text { Ref. }\end{array}$

(B) Academic and community multispecialty hospitals only

Patients who required flights and/or lodging/meals, \%

$1.4 \quad 30.4^{* * *}$

Costs

Patient

$\$ 482,954$

$\$ 1,117,184$

$\$ 22,999$

$\$ 8,333,748$

$\$ 9,956,884$

Caregiver

$\$ 1,400,565$

$\$ 2,216,665$

$\$ 22,999$

$\$ 3,502,369$

$\$ 7,142,598$

Total

$\$ 1,883,519$

$\$ 3,333,849$

$\$ 45,997$

$\$ 11,836,117$

$\$ 17,099,482$

Difference from scenario A $\quad(\$ 256,297)$

$(\$ 1,121,068)$

$(\$ 16,651) \quad(\$ 2,629,373)$

$(\$ 4,023,389)$

(C) Any specialized treatment facility

Patients who required flights and/or lodging/meals, \%

$0.5^{* * *} \quad 26.2^{* * *}$

Costs

$\begin{array}{ll}\text { Patient } & \$ 466,087 \\ \text { Caregiver } & \$ 1,351,653 \\ \text { Total } & \$ 1,817,740\end{array}$

$\$ 1,107,887$

$\$ 8934 \quad \$ 6,778,134$

$\$ 8,361,043$

Difference from scenario A $\quad(\$ 322,075)$

$\$ 1,998,276$

$\$ 8934$

$\$ 2,941,107$

$\$ 6,299,969$

$\$ 3,106,163$

$\$ 17,868$

$\$ 9,719,241$

$\$ 14,661,012$

Weighted mean costs per patient

(A) Academic hospitals only

$\begin{array}{llllll}\text { Patient } & \$ 139 & \$ 380 & \$ 8 & \$ 2594 & \$ 3121 \\ \text { Caregiver } & \$ 404 & \$ 752 & \$ 8 & \$ 1082 & \$ 2246 \\ \text { Total } & \$ 544 & \$ 1132 & \$ 16 & \$ 3676 & \$ 5368 \\ & \text { Ref. } & \text { Ref. } & \text { Ref. } & \text { Ref. } & \text { Ref. }\end{array}$

(B) Academic and community multispecialty hospitals only

\begin{tabular}{|c|c|c|c|c|c|}
\hline Patient & $\$ 123$ & $\$ 283$ & $\$ 6$ & $\$ 2114$ & $\$ 2526$ \\
\hline Caregiver & $\$ 355$ & $\$ 562$ & $\$ 180$ & $\$ 889$ & $\$ 1986$ \\
\hline Total & $\$ 478$ & $\$ 846$ & $\$ 185$ & $\$ 3003$ & $\$ 4512^{* *}$ \\
\hline Difference from scenario A & $(\$ 66)$ & $(\$ 286)$ & $(\$ 169)$ & $(\$ 673)$ & $(\$ 856)$ \\
\hline
\end{tabular}


Table 1 continued

\begin{tabular}{|c|c|c|c|c|c|}
\hline Scenario & Driving-related costs & Indirect costs & Flights & Lodging and meals & Total costs \\
\hline \multicolumn{6}{|c|}{ (C) Any specialized treatment facility } \\
\hline Patient & $\$ 119$ & $\$ 282$ & $\$ 2$ & $\$ 1728$ & $\$ 2132$ \\
\hline Caregiver & $\$ 345$ & $\$ 509$ & $\$ 2$ & $\$ 750$ & $\$ 1606$ \\
\hline Total & $\$ 463$ & $\$ 792$ & $\$ 5$ & $\$ 2478$ & $\$ 3738^{* * *}$ \\
\hline Difference from scenario A & $(\$ 80)$ & $(\$ 340)$ & $(\$ 11)$ & $(\$ 1198)$ & $(\$ 1630)$ \\
\hline
\end{tabular}

Values may not sum due to rounding

Ref. reference

${ }^{*} P \leq 0.05,{ }^{* *} P \leq 0.01,{ }^{* * *} P \leq 0.001$

\section{DISCUSSION}

This study joins a small but growing body of literature that highlights the importance of access to different SOC types, particularly for novel therapies [41, 42]. We found that expected travel burden was consistently reduced at the national and regional levels by expanding CAR T cell therapy access to additional SOC types. The estimated cost difference was substantial, with the $\$ 1630$ per-patient savings between scenario A and scenario C comparable to the total patient out-of-pocket expense for lymphoma treatment in the month of diagnosis ( \$1200) [43].

Distance and time to the nearest administering facility are key drivers of cost-variables that can be reduced by expanding care. However, in many cases, increasing access to community hospitals was insufficient to significantly reduce travel burden. This nonsignificant reduction occurred in the northeast and south regions, urban areas, and Black and Native American race groups. In contrast, expanding access to NASONCs significantly reduced travel costs among all groups and regions.

The estimated economic burden was highest among patients residing in the west and rural regions, patients of White or Native American race, and those living below the FPL. For many of these populations, high travel burden may represent a true barrier to accessing therapy. The federal poverty guideline for a household of two in 2019 was an income of $\$ 16,910$ [19]. In our analysis, mean travel costs for both scenarios were a significant percentage of this income level ( $\$ 5588$ for scenario A [33\% of the FPL] and $\$ 3970$ for scenario C [23\% of the FPL]). Thus, cost savings (\$1619) between scenario A and scenario C represented $10 \%$ of this threshold income level, which is a consequential saving.

Expected travel burden may increase further under scenario A if capacity is restricted for novel therapies. Academic hospitals, while large and reputable, are limited in number. Patients would be expected to travel farther distances and thus incur higher costs if only a small number of centers can gain experience administering novel therapies because of network limitations or other reimbursement restrictions.

Costs to establish a CAR T cell program by setting of care (e.g., in community settings compared with community hospitals and academic centers of excellence) may vary. The investment costs have not been estimated; however, in any setting of care, providers in the CAR T cell therapy unit will require focused education consistent with standards provided by the Foundation for the Accreditation of Cellular Therapy (FACT) [44, 45]. Logistical considerations for CAR T cell therapy administration in any setting would include room design to minimize risk of infection and hours 
Table 2 Total weighted mean economic burden per patient and caregiver by region and demographic characteristics

\section{Regional results}

\begin{tabular}{|c|c|c|c|c|c|c|c|}
\hline Scenario & National & Midwest & Northeast & South & West & Rural & Urban \\
\hline \multicolumn{8}{|l|}{ (A) Academic hospitals only } \\
\hline Patient & $\$ 3121$ & $\$ 3320$ & $\$ 2129$ & $\$ 3632$ & $\$ 6430$ & $\$ 4204$ & $\$ 2679$ \\
\hline Caregiver & $\$ 2246$ & $\$ 2639$ & $\$ 1791$ & $\$ 2279$ & $\$ 4607$ & $\$ 2988$ & $\$ 1945$ \\
\hline \multirow[t]{2}{*}{ Total } & $\$ 5368$ & $\$ 5959$ & $\$ 3920$ & $\$ 5911$ & $\$ 11,037$ & $\$ 7191$ & $\$ 4625$ \\
\hline & Ref. & Ref. & Ref. & Ref. & Ref. & Ref. & Ref. \\
\hline \multicolumn{8}{|c|}{ (B) Academic and community multispecialty hospitals only } \\
\hline Patient & $\$ 2526$ & $\$ 3063$ & $\$ 1652$ & $\$ 3204$ & $\$ 6027$ & $\$ 3931$ & $\$ 2308$ \\
\hline Caregiver & $\$ 1812$ & $\$ 2571$ & $\$ 1423$ & $\$ 2089$ & $\$ 3007$ & $\$ 2682$ & $\$ 1691$ \\
\hline Total & $\$ 4338^{* *}$ & $\$ 5634^{* *}$ & $\$ 3075$ & $\$ 5293$ & $\$ 9034^{* * *}$ & $\$ 6613^{*}$ & $\$ 3998$ \\
\hline Difference from scenario A & $(\$ 1030)$ & $(\$ 325)$ & $(\$ 846)$ & $(\$ 618)$ & $(\$ 2003)$ & $(\$ 578)$ & $(\$ 626)$ \\
\hline \multicolumn{8}{|c|}{ (C) Any specialized treatment facility } \\
\hline Patient & $\$ 2132$ & $\$ 2649$ & $\$ 1327$ & $\$ 2573$ & $\$ 2187$ & $\$ 3142$ & $\$ 1765$ \\
\hline Caregiver & $\$ 1606$ & $\$ 2332$ & $\$ 1260$ & $\$ 1931$ & $\$ 1656$ & $\$ 2149$ & $\$ 1476$ \\
\hline Total & $\$ 3738^{* * *}$ & $\$ 4981^{* *}$ & $\$ 2587^{* * *}$ & $\$ 4504^{*}$ & $\$ 3843^{* * *}$ & $\$ 5291^{* * *}$ & $\$ 3241^{* * *}$ \\
\hline Difference from scenario A & $(\$ 1630)$ & (\$978) & $(\$ 1333)$ & $(\$ 1407)$ & $(\$ 7194)$ & $(\$ 1900)$ & $(\$ 1384)$ \\
\hline
\end{tabular}

Demographic results

\begin{tabular}{lllllll}
\hline Scenario & Asian & Black & Hispanic Native American White & $<100 \%$ FPL $\geq 100 \%$ FPL
\end{tabular}

(A) Academic hospitals only

$\begin{array}{llllllll}\text { Patient } & \$ 1553 & \$ 2670 & \$ 2766 & \$ 5017 & \$ 3393 & \$ 3292 & \$ 3070 \\ \text { Caregiver } & \$ 1996 & \$ 3165 & \$ 3280 & \$ 6087 & \$ 3938 & \$ 2296 & \$ 2231 \\ \text { Total } & \$ 3549 & \$ 5835 & \$ 6046 & \$ 11,104 & \$ 7331 & \$ 5588 & \$ 5301 \\ & \text { Ref. } & \text { Ref. } & \text { Ref. } & \text { Ref. } & \text { Ref. } & \text { Ref. } & \text { Ref. }\end{array}$

(B) Academic and community multispecialty hospitals only

\begin{tabular}{llllllll} 
Patient & $\$ 1199$ & $\$ 2152$ & $\$ 2261$ & $\$ 4479$ & $\$ 2739$ & $\$ 2703$ & $\$ 2473$ \\
Caregiver & $\$ 1547$ & $\$ 2565$ & $\$ 2665$ & $\$ 5220$ & $\$ 3180$ & $\$ 1884$ & $\$ 1791$ \\
Total & $\$ 2746^{*}$ & $\$ 4717$ & $\$ 4926^{*}$ & $\$ 9699$ & $\$ 5920^{*}$ & $\$ 4586^{* *}$ & $\$ 4264^{* *}$ \\
$\begin{array}{l}\text { Difference in site scenarios } \\
(\mathrm{C}) \text { Any specialized treatment facility }\end{array}$ & $\$ 804)$ & $(\$ 1118)$ & $(\$ 1120)$ & $(\$ 1406)$ & $(\$ 1412)$ & $(\$ 1002)$ & $(\$ 1038)$ \\
$\begin{array}{l}\text { Patient } \\
\text { Caregiver }\end{array}$ & $\$ 1041$ & $\$ 1763$ & $\$ 1920$ & $\$ 3149$ & & & \\
Total & $\$ 1365$ & $\$ 2158$ & $\$ 2265$ & $\$ 3783$ & $\$ 2329$ & $\$ 2294$ & $\$ 2083$ \\
\hline
\end{tabular}


Table 2 continued

Demographic results

\begin{tabular}{llllllll}
\hline Scenario & Asian & Black & Hispanic & Native American & White & $<$ 100\% FPL & $\mathbf{2} 100 \%$ FPL \\
\hline Difference in site scenarios & $(\$ 1144)$ & $(\$ 1915)$ & $(\$ 1861)$ & $(\$ 4173)$ & $(\$ 2327)$ & $(\$ 1619)$ & $(\$ 1633)$ \\
\hline
\end{tabular}

Values may not sum due to rounding

FPL federal poverty level, Ref. reference

${ }^{*} P \leq 0.05,{ }^{* *} P \leq 0.01,{ }^{* * *} P \leq 0.001 . \mathrm{Z}$ proportion test

to support infusion, monitoring, and time for potential manufacturing delays.

The CAR T cell therapy process has many steps, including leukapheresis or lymphocyte collection, transportation of the collected cells to a laboratory, cell engineering, patient conditioning with lymphodepleting chemotherapy, followed by infusion, patient monitoring and follow-up. Many of these steps can and currently are being performed at the nearest blood center, clinic, or infusion center; however, considerable unnecessary costs are incurred if the patient must travel to an academic hospital or community multispecialty hospital for the infusion, as shown in the extreme sensitivity analysis in which we excluded lodging costs.

Although economic burden may not be entirely realized by the patient or payer, the value of time spent traveling and costs borne by any entity represent suboptimal resource use and potential barriers to care. Pharmaceutical manufacturers and commercial insurance providers have developed patient assistance programs to alleviate the impact of some travelrelated direct costs. Manufacturers and payers may be obligated to compensate higher amounts if, on average, patients are traveling farther distances to receive care at academic hospitals. Moreover, patients may be exposed to higher out-of-pocket costs if the assistance programs do not sufficiently cover the high burden associated with traveling to academic hospitals. In both cases, economic inefficiency is realized by restricted SOC access. Beyond the direct costs borne by any stakeholder, indirect
Fig. 2 Cost distribution across geographic regions for each scenario

costs generated by unproductive and potentially uncomfortable excessive travel represent an unnecessary fee to society and patients' overall well-being. Our study attempted to value the total economic burden imposed on patients and caregivers, with a focus on travel burden.

Over time, health care payers and pharmaceutical manufacturers have developed de facto centers of excellence networks that have influenced patient access to novel oncology therapies. Manufacturers have established networks of providers in the clinical trials phase, with the goal of achieving consistent practice and low complication rates. Many large payers have developed language in their coverage plans that restrict or encourage referrals to a select subset of providers or centers of excellence. These networks will expand over time, while patient access will be determined by both payer-defined and manufacturer qualifications for administration of therapies, in addition to potential restrictions imposed by the US Food and Drug Administration and governmental payers, including the Centers for Medicare \& Medicaid Services.

This study has several limitations. Not all patients with relapsed/refractory DLBCL would be candidates for or elect to receive CAR T cell therapy. Our study assumed that all eligible patients with relapsed/refractory DLBCL would 


\section{Total Weighted Mean Cost per Patient (\$)}

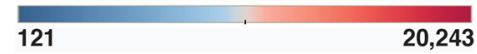

\section{Scenario A}

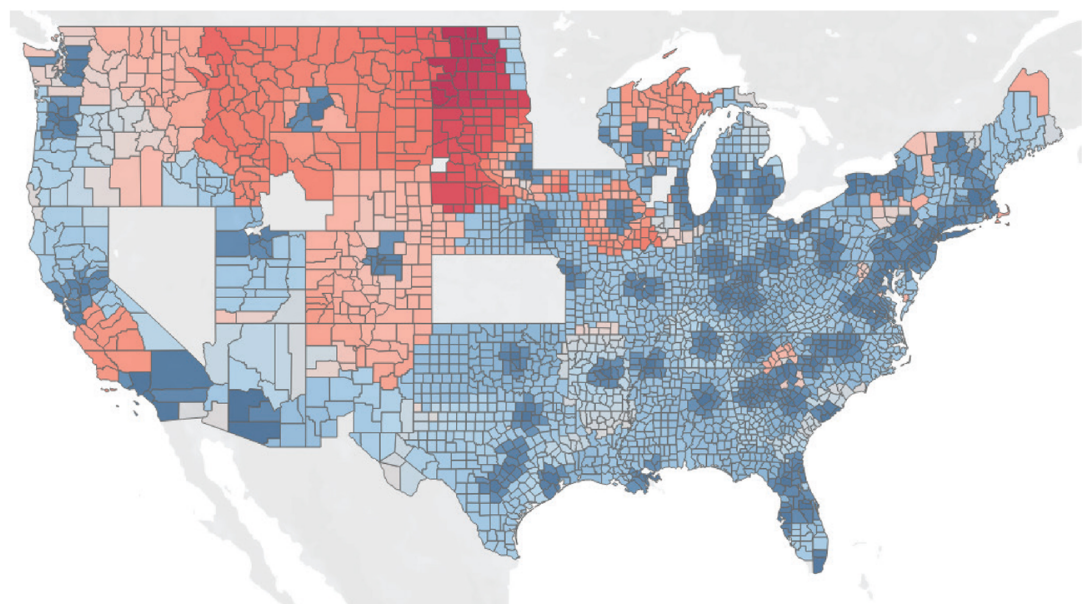

Scenario B

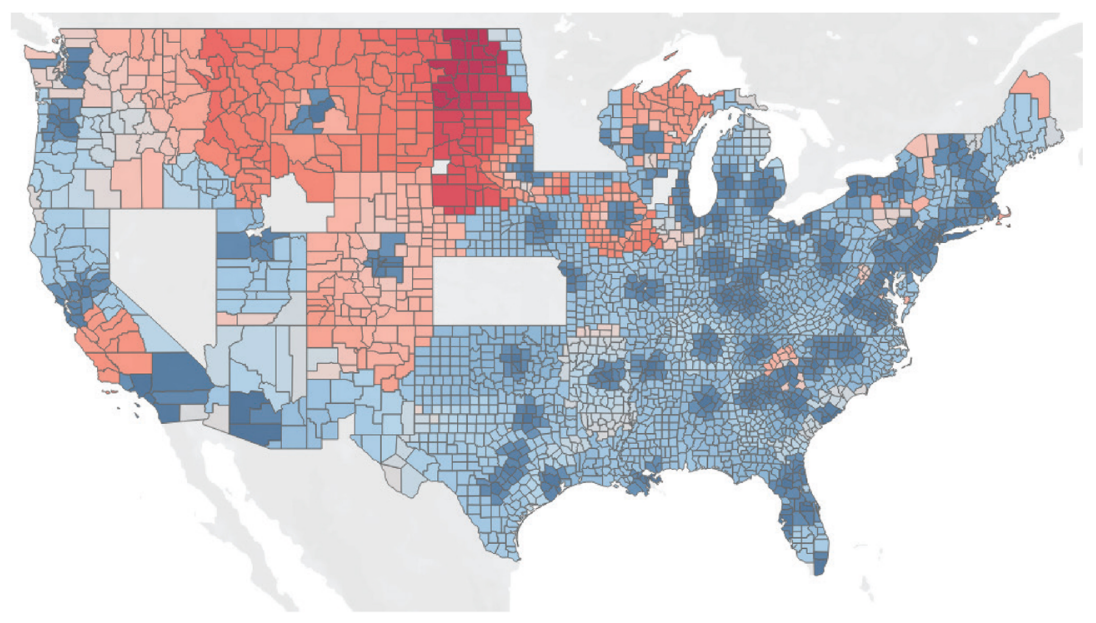

Scenario C

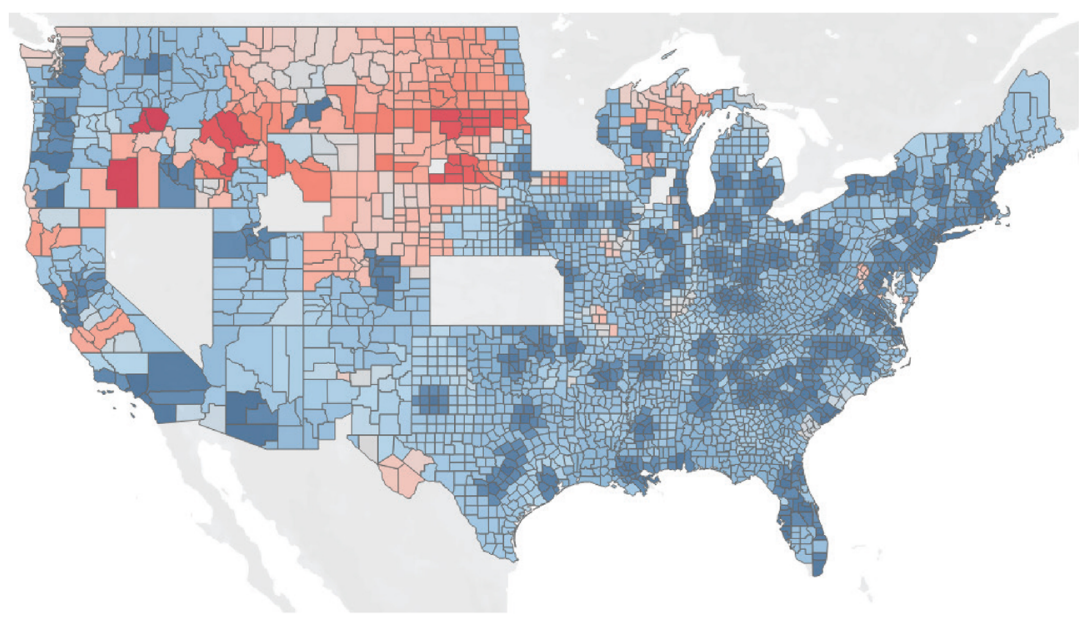




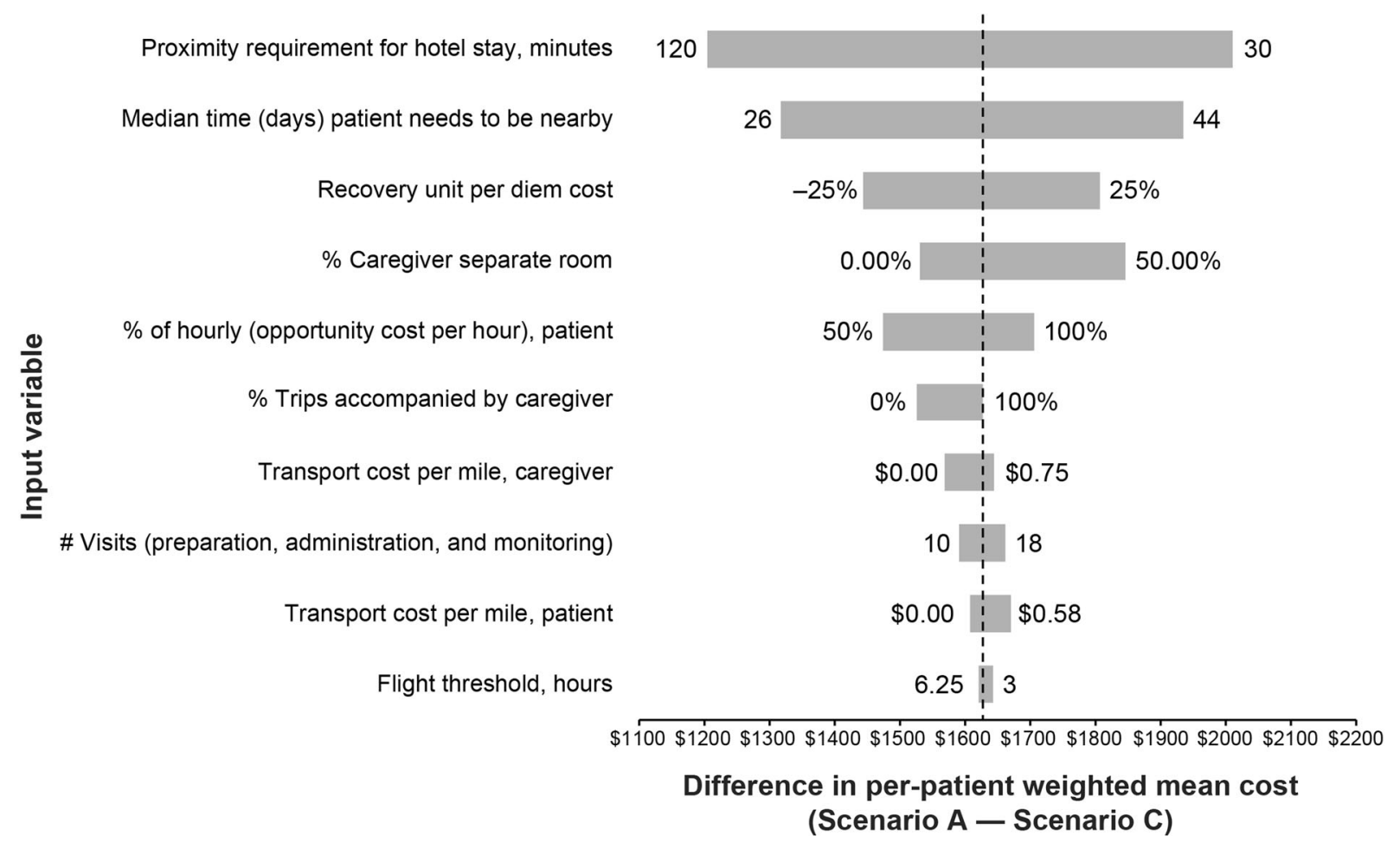

Fig. 3 One-way deterministic sensitivity analysis

receive CAR T cell therapy; however, a change in the number of patients receiving care would maintain the relative difference between expected travel costs. Additionally, some nonacademic centers may not be equipped to manage patients with comorbidities or predisposing factors after CAR T cell therapy administration, and these patients may require treatment at an academic center. The current landscape of CAR T cell therapy administration sites may have changed since the beginning of 2019, and some states were not included as noted previously [9]. Furthermore, we cannot unequivocally attribute exact costs to patient travel using modeling methods, though the analysis offers important directional insight into the scale of the impact of SOC access for novel therapies.

The inclusion of SOCs specified by available CAR T cell therapy limits the generalizability of the findings to other cancer types. As a descriptive study, this research did not attempt to make causal inferences between geographic access and receipt of therapy or patient outcomes, yet it provides the foundation for this next logical step. Patient incidence data for NHL and DLBCL incidence was estimated as a proportion of NHL using the literature on DLBCL. We assumed there was no geographic variation in DLBCL as a proportion of NHL, which may not be precise; however, the comparability of the scenarios should not be impacted, as these data were applied to all analyses.

\section{CONCLUSION}

At the national level, total economic travel burden would decrease by approximately $31 \%$ if access to CAR T cell therapy was expanded from a scenario of academic hospitals only to nonacademic hospitals and specialty oncology centers. Patients in rural areas and those living below the FPL are particularly disadvantaged by restricted access. These findings will help policy- and decision-makers consider regional, rural-urban, and sociodemographic inequalities 
in the geographic allocation of CAR T cell therapy to maximize access to this therapy and other novel treatment modalities.

\section{ACKNOWLEDGEMENTS}

Funding. This research was funded by Bristol Myers Squibb. The study sponsor is also funding the journal's Rapid Service and Open Access fees.

Medical Writing and Editorial Assistance. Medical writing, graphics, and editorial support were provided by Meredith Rogers, MS, CMPP, and Edwin Thrower, PhD, of The Lockwood Group (Stamford, CT), funded by Bristol Myers Squibb.

Prior Presentation. This research was presented in part at the Academy of Managed Care Pharmacy (AMCP) Annual Meeting in Houston, Texas, April 23, 2020.

Authorship. All named authors meet the International Committee of Medical Journal Editors (ICMJE) criteria for authorship for this article, take responsibility for the integrity of the work as a whole, and have given their approval for this version to be published.

Authorship Contributions. All authors had full access to the data in the study and take responsibility for the integrity of the data, the relevance of the methodology, and the accuracy of the data analysis. Matthew Gitlin, Monika P. Jun, and Sophie Snyder were involved in study concept and design. Sophie Snyder was responsible for collection and assembly of data. Sophie Snyder, Tina Albertson, and Jacob Garcia carried out data analysis and interpretation. Sophie Snyder was involved in writing the manuscript. All authors approved of the manuscript and were accountable for all aspects of the work.

Disclosures. Sophie Snyder is an employee of BluePath Solutions, which received funding from Bristol Myers Squibb, to perform the analyses. Tina Albertson is a former employee of Bristol Myers Squibb. Jacob Garcia is a former employee of Bristol Myers Squibb, and may own stock and/or hold stock options in Bristol Myers Squibb. Matthew Gitlin is an employee of BluePath Solutions, which received funding from Bristol Myers Squibb, to perform the analyses. Monika P. Jun is an employee of Bristol Myers Squibb, and may own and/or hold stock options in Bristol Myers Squibb.

Compliance with Ethics Guidelines. This article does not contain any new studies with human participants or animals performed by any of the authors.

Data Availability. All data generated or analyzed during this study are included in this published article.

Open Access. This article is licensed under a Creative Commons Attribution-NonCommercial 4.0 International License, which permits any non-commercial use, sharing, adaptation, distribution and reproduction in any medium or format, as long as you give appropriate credit to the original author(s) and the source, provide a link to the Creative Commons licence, and indicate if changes were made. The images or other third party material in this article are included in the article's Creative Commons licence, unless indicated otherwise in a credit line to the material. If material is not included in the article's Creative Commons licence and your intended use is not permitted by statutory regulation or exceeds the permitted use, you will need to obtain permission directly from the copyright holder. To view a copy of this licence, visit http://creativecommons.org/licenses/by$\mathrm{nc} / 4.0 /$.

\section{REFERENCES}

1. Teras LR, DeSantis CE, Cerhan JR, Morton LM, Jemal A, Flowers CR. 2016 US lymphoid malignancy statistics by World Health Organization subtypes. CA Cancer J Clin. 2016;66(6):443-59. https://doi.org/10.3322/caac.21357. 
2. Molina A. A decade of rituximab: improving survival outcomes in non-Hodgkin's lymphoma. Annu Rev Med. 2008;59:237-50. https://doi.org/10.1146/ annurev.med.59.060906.220345.

3. Narang AK, Nicholas LH. Out-of-pocket spending and financial burden among Medicare beneficiaries with cancer. JAMA Oncol. 2017;3(6):757-65. https://doi.org/10.1001/jamaoncol.2016.4865.

4. Heydarnejad MS, Hassanpour DA, Solati DK. Factors affecting quality of life in cancer patients undergoing chemotherapy. Afr Health Sci. 2011;11(2): 266-70.

5. Yin W, Horblyuk R, Perkins JJ, et al. Association between breast cancer disease progression and workplace productivity in the United States. J Occup Environ Med. 2017;59(2):198-204. https:// doi.org/10.1097/jom.0000000000000936.

6. National Cancer Institute. NCI-designated cancer centers. 2019. https://www.cancer.gov/research/ infrastructure/cancer-centers. Accessed 21 Sept 2020.

7. Kirkwood MK, Hanley A, Bruinooge SS, et al. The state of oncology practice in America, 2018: results of the ASCO Practice Census Survey. J Oncol Pract. 2018;14(7):e412-20. https://doi.org/10.1200/JOP. 18.00149 .

8. Novartis. Find a KYMRIAH treatment center. 2020. https://www.us.kymriah.com/treatment-centerlocator/. Accessed 31 Jan 2020.

9. Snyder S, Chung KC, Jun MP, Gitlin M. Access to chimeric antigen receptor $T$ cell therapy for diffuse large B cell lymphoma. Adv Ther. 2021. https://doi. org/10.1007/s12325-021-01838-z.

10. Zafar SY, Peppercorn JM, Schrag D, et al. The financial toxicity of cancer treatment: a pilot study assessing out-of-pocket expenses and the insured cancer patient's experience. Oncologist. 2013;18(4): 381-90. https://doi.org/10.1634/theoncologist. 2012-0279.

11. Banegas MP, Guy GP Jr, de Moor JS, et al. For working-age cancer survivors, medical debt and bankruptcy create financial hardships. Health Aff (Millwood). 2016;35(1):54-61. https://doi.org/10. 1377/hlthaff.2015.0830.

12. Ramsey S, Blough D, Kirchhoff A, et al. Washington State cancer patients found to be at greater risk for bankruptcy than people without a cancer diagnosis. Health Aff (Millwood). 2013;32(6):1143-52. https:// doi.org/10.1377/hlthaff.2012.1263.

13. Ramsey SD, Bansal A, Fedorenko CR, et al. Financial insolvency as a risk factor for early mortality among patients with cancer. J Clin Oncol. 2016;34(9): 980-6. https://doi.org/10.1200/JCO.2015.64.6620.

14. Dieguez G, Ferro C, Pyenson BS. Milliman research report: a multi-year look at the cost burden of cancer care. 2017. https://milliman-cdn.azureedge. net/-/media/milliman/importedfiles/uploadedfiles/ insight/2017/cost-burden-cancer-care.ashx. Accessed 31 Jan 2020.

15. Mariotto AB, Yabroff KR, Shao Y, Feuer EJ, Brown ML. Projections of the cost of cancer care in the United States: 2010-2020. J Natl Cancer Inst. 2011;103(2):117-28. https://doi.org/10.1093/jnci/ djq495.

16. Casalino LP, Devers KJ, Brewster LR. Focused factories? Physician-owned specialty facilities. Health Aff (Millwood). 2003;22(6):56-67. https://doi.org/ 10.1377/hlthaff.22.6.56.

17. Onega T, Duell EJ, Shi X, Wang D, Demidenko E, Goodman D. Geographic access to cancer care in the US. Cancer. 2008;112(4):909-18. https://doi. org/10.1002/cncr.23229.

18. Schuster SJ, Bishop MR, Tam CS, et al. Tisagenlecleucel in adult relapsed or refractory diffuse large B-cell lymphoma. N Engl J Med. 2019;380(1):45-56. https://doi.org/10.1056/NEJMoa1804980.

19. Neelapu SS, Locke FL, Bartlett NL, et al. Axicabtagene ciloleucel CAR T-cell therapy in refractory large B-cell lymphoma. N Engl J Med. 2017;377(26): 2531-44. https://doi.org/10.1056/NEJMoa1707447.

20. Kite Pharma. Where can YESCARTA ${ }^{\circledR}$ be received? 2019. https://www.yescarta.com/treatment-centers. Accessed 31 Jan 2020.

21. National Cancer Institute. Find a cancer center. 2020. https://www.cancer.gov/research/nci-role/ cancer-centers/find. Accessed 31 Jan 2020.

22. Centers for Medicare \& Medicaid Services. Oncology care model practice list. 2020. https:// innovation.cms.gov/initiatives/Oncology-Care/. Accessed 31 Jan 2020.

23. Association of Community Cancer Centers. Find a cancer program. 2020. https://www.accc-cancer. org/. Accessed 31 Jan 2020.

24. General Services Administration. Per diem rates. 2019. https://www.gsa.gov/travel/plan-book/perdiem-rates. Accessed 11 Mar 2020.

25. Bureau of Transportation Statistics. Average domestic airline itinerary fares. 2019. https://www. transtats.bts.gov/AverageFare/Default.aspx. Accessed 11 Mar 2020. 
26. Bureau of Labor Statistics. Overview of BLS wage data by area and occupation. 2020. https://www. bls.gov/bls/blswage.htm\#. Accessed 30 June 2020.

27. Internal Revenue Service. Standard mileage rates. $2019 . \quad$ https://www.irs.gov/tax-professionals/ standard-mileage-rates. Accessed 11 Mar 2020.

28. US Census Bureau. 2011-2015 ACS 5-year estimates. 2019. https://www.census.gov/programssurveys/acs/technical-documentation/table-andgeography-changes/2015/5-year.html. Accessed 31 Jan 2020.

29. Stephens JM, Li X, Reiner M, Tzivelekis S. Annual patient and caregiver burden of oncology clinic visits for granulocyte-colony stimulating factor therapy in the US. J Med Econ. 2016;19(5):537-47. https://doi.org/10.3111/13696998.2016.1140052.

30. Verbooy K, Hoefman R, van Exel J, Brouwer W. Time is money: investigating the value of leisure time and unpaid work. Value Health. 2018;21(12): 1428-36. https://doi.org/10.1016/j.jval.2018.04. 1828.

31. Hagberg LA, Lindholm L. Measuring the time costs of exercise: a proposed measuring method and a pilot study. Cost Eff Resour Alloc. 2010;8:9. https:// doi.org/10.1186/1478-7547-8-9.

32. Freedman AS, Friedberg JW. Patient education: diffuse large B cell lymphoma in adults (beyond the basics). UpToDate. 2019. https://www.uptodate. com/contents/diffuse-large-b-cell-lymphoma-inadults-beyond-the-basics. Accessed 31 Jan 2020.

33. Business Management Daily Editors. Business travel: use '5-hour rule' in drive vs. fly decision. 2007. https://www.businessmanagementdaily.com/ 23987/business-travel-use-5-hour-rule-in-drive-vsfly-decision/. Accessed 31 Jan 2020.

34. Centers for Medicare \& Medicaid Services. Glossary and acronyms. 2016. https://www.cms.gov/ OpenPayments/About/Glossary-and-Acronyms. Accessed 31 Jan 2020.

35. Centers for Medicare \& Medicaid Services. Open payments 2019 reporting cycle teaching hospital list. 2020. https://www.cms.gov/OpenPayments/ Downloads/2019-Reporting-Cycle-TeachingHospital-List-pdf.pdf. Accessed 31 Jan 2020.

36. Wilemon T. VICC launches new telehealth program for CAR-T patients. Vanderbilt University Medical Center; 2019. http://news.vumc.org/2019/02/28/ vicc-launches-new-telehealth-program-for-car-tpatients/. Accessed 31 Jan 2020.
37. Office of the Federal Register. Electronic code of federal regulations. Title 42: Public Health. Part 5-Designation of Health Professional(s) Shortage Areas. 1992. https://www.ecfr.gov/cgi-bin/retrieve ECFR?gp=1\&SID=c82fffd7d1451077b6744cdbf8c8 $438 \mathrm{f} \& \mathrm{ty}=\mathrm{HTML} \& \mathrm{~h}=\mathrm{L} \& \mathrm{mc}=$ true $\& \mathrm{r}=\mathrm{APPENDIX} \& \mathrm{n}=$ ap42.1.5_14.a. Accessed 28 Jan 2020.

38. Rovira J, Valera A, Colomo L, et al. Prognosis of patients with diffuse large B cell lymphoma not reaching complete response or relapsing after frontline chemotherapy or immunochemotherapy. Ann Hematol. 2015;94(5):803-12. https://doi.org/ 10.1007/s00277-014-2271-1.

39. Van Den Neste E, Schmitz N, Mounier N, et al. Outcomes of diffuse large B-cell lymphoma patients relapsing after autologous stem cell transplantation: an analysis of patients included in the CORAL study. Bone Marrow Transplant. 2017;52(2): 216-21. https://doi.org/10.1038/bmt.2016.213.

40. Surveillance, Epidemiology, and End Results (SEER) Program. SEER*Stat Database: incidence-SEER 9 Regs Research Data, Nov 2018 Sub (1975-2016) $<$ Katrina/Rita Population Adjustment $>.2019$. http://www.seer.cancer.gov. Accessed 28 May 2019.

41. Kelly C, Hulme C, Farragher T, Clarke G. Are differences in travel time or distance to healthcare for adults in global north countries associated with an impact on health outcomes? A systematic review. BMJ Open. 2016;6(11): e013059. https://doi.org/10. 1136/bmjopen-2016-013059.

42. Maddison AR, Asada $\mathrm{Y}$, Urquhart R. Inequity in access to cancer care: a review of the Canadian literature. Cancer Causes Control. 2011;22(3):359-66. https://doi.org/10.1007/s10552-010-9722-3.

43. Fitch K, Ferro C, Pittinger S. Milliman research report. The cost burden of blood cancer care in Medicare: a longitudinal analysis of Medicare Advantage and Fee for Service patients diagnosed with blood cancer. 2019. https://milliman-cdn. azureedge.net/-/media/milliman/importedfiles/ektr on/cost_of_blood_cancer_in_medicare_20191016.a shx. Accessed 31 Jan 2020.

44. Perica K, Curran KJ, Brentjens RJ, Giralt SA. Building a CAR garage: preparing for the delivery of commercial CAR T cell products at Memorial Sloan Kettering Cancer Center. Biol Blood Marrow Transplant. 2018;24(6):1135-41. https://doi.org/10. 1016/j.bbmt.2018.02.018.

45. Taylor L, Rodriguez ES, Reese A, Anderson K. Building a program: implications for infrastructure, nursing education, and training for CAR T-cell therapy. Clin J Oncol Nurs. 2019;23(2):20-6. https://doi.org/10.1188/19.CJON.S1.20-26. 